Cite this paper as: Ruiz-Teran AM, Aparicio AC, 2009, Response of under-deck cable-stayed bridges to the accidental breakage of stay cables, Engineering Structures, Vol:31, ISSN:0141-0296,

Pages:1425-1434 [DOI: 10.1016/j.engstruct.2009.02.027]

\title{
Response of under-deck cable-stayed bridges to the accidental
}

\section{breakage of stay cables.}

\author{
A. M. Ruiz-Teran ${ }^{\mathrm{a}, 1}$, A. C. Aparicio ${ }^{\mathrm{b}}$ \\ ${ }^{a}$ Principal Lecturer in Structural Engineering. School of Computing, Information Technology and \\ Engineering, University of East London, 4-6 University Way, E16 2RD London, UK.
}

${ }^{\mathrm{b}}$ Professor in Bridge Engineering. Department of Construction Engineering, Technical University of Catalonia, C/Jordi Girona, 1-3, 08034 Barcelona, Spain

${ }^{1}$ Corresponding address: Tel: +44 2082233289 Fax: +44 2082232963

E-mail address: a.m.ruiz-teran@uel.ac.uk; aruiter@ciccp.es (A. M. Ruiz-Teran), angel.carlos.aparicio@upc.es (A. C. Aparicio) 
Cite this paper as: Ruiz-Teran AM, Aparicio AC, 2009, Response of under-deck cable-stayed bridges to the accidental breakage of stay cables, Engineering Structures, Vol:31, ISSN:0141-0296, Pages:1425-1434 [DOI: 10.1016/j.engstruct.2009.02.027]

\section{ABSTRACT}

Under-deck cable-stayed bridges with prestressed concrete decks have recently been shown to be appropriate structural types for highway overpasses. However, doubts have emerged regarding their capability to withstand the accidental breakage of stay cables, due to collisions with heavy vehicles, without collapsing. In this paper, two distinct parametric analyses are conducted on two different bridges, each of which is representative of this bridge type, in order to study their response due to the breakage of stay cables. The response is assessed through fully dynamic analyses, rather than pseudodynamic analysis (via the use of dynamic amplification factors), since the latter method has been shown to be un-conservative in some cases. In both parametric analyses different scenarios, i.e., different parameters, relating to the type of breakage, the time over which breakage occurs, the number of broken stay cables, the type of deviators and the amount of applied traffic live load are considered. In the present study, the capability of this bridge type to easily overcome this accidental action, with a higher degree of safety than that required by codes, is clearly demonstrated. In fact, the analysed bridges do not reach any ultimate limit-state even if $40 \%$ of their stay cables are suddenly broken when $100 \%$ of the traffic live load is applied. In addition, a set of design criteria closely related with this issue are established.

\section{KEY WORDS}

Breakage of cables; loss of a cable; stay cables; under-deck cable-stayed bridges; prestressed concrete bridges; bridge design 
Cite this paper as: Ruiz-Teran AM, Aparicio AC, 2009, Response of under-deck cable-stayed bridges to the accidental breakage of stay cables, Engineering Structures, Vol:31, ISSN:0141-0296, Pages:1425-1434 [DOI: 10.1016/j.engstruct.2009.02.027]

\section{INTRODUCTION}

Under-deck cable-stayed bridges (Fig. 1) represent an innovative bridge type that has only been built on a few occasions over the last thirty years. Structural engineers such as Leonhardt [1], Schlaich [2], Virlogeux [3], Manterola [4] and Cremer [5] have designed bridges with this structural type. Under-deck cable-stayed bridges are a particular type of cable-stayed bridge in which the stay cables are located below the deck and are deviated through struts that, working under compression, introduce the cable deviation forces into the deck. The stay cables, which obviously work under tension, are self-anchored in the deck in the support sections over the abutments and piers (when these exist). The deck works both in compression and bending. Therefore, the structural behaviour of the bridge is a combination of axial and flexural response. Ruiz-Teran and Aparicio have outlined the state-of-the-art of this bridge type [6], have identified the parameters that govern its structural response [7], studied its structural behaviour and have proposed design criteria for both single-span [8] and multi-span [9] bridges of this type. Multiple advantages from different standpoints (structural efficiency, construction possibilities, economic and aesthetic considerations) have been identified through comparison with conventional bridges without stay cables [8,9]. Despite these advantages, proposals for construction using this bridge type have come up against resistance; such as in the case of the Kirchheim overpass. In 1987, Schlaich was given the job of designing a bridge with under-deck stay cables for the Kirchheim overpass [2]. He designed a portal frame with a main span of $45.2 \mathrm{~m}$ in which a slender deck of $0.40 \mathrm{~m}$ was supported by under-deck cables [10]. However, this innovative structure was not built because the state authority feared the possibility of the bridge collapsing in the case of a lorry with an extremely high load, above the legal limit, crashing into the under-deck cables and causing their sudden breakage [2].

Provided that there is sufficient clearance beneath the stay cables, this bridge type has been shown to be very appropriate for use in highway overpasses [8]. Therefore, the aim of this paper is to study the response of these bridges in the situation of accidental breakage of stay cables in order to prove that this bridge type has more capacity to overcome the sudden accidental breakage of stay cables than that required by codes. In this unlikely scenario, repair could easily be carried out without 
Cite this paper as: Ruiz-Teran AM, Aparicio AC, 2009, Response of under-deck cable-stayed bridges to the accidental breakage of stay cables, Engineering Structures, Vol:31, ISSN:0141-0296, Pages:1425-1434 [DOI: 10.1016/j.engstruct.2009.02.027]

affecting the traffic, provided that this circumstance had been considered during the design stage following appropriate design criteria. The study focuses on two different bridges that are each representative of this bridge type. The response of these two bridges under the accidental breakage of the stay cables in different potential scenarios is analysed by means of parametric analyses. In addition, the dynamic structural response following the breakage of the stay cables is obtained through time-domain analyses, rather than by pseudo-dynamic analyses using dynamic amplification factors $(D A F)$. The latter method, that has been recommended by several associations (PTI [11], SETRA [12] and ACHE [13]) in their design guidelines for cable-stayed bridges, and that is also proposed implicitly in Eurocode 3 Part 1.11 [14] and explicitly in Eurocode 1 Part 1.7 [15], has been shown to be un-conservative [16], and thus inadvisable, for certain cases, such as those studied herein. This paper concludes with a set of recommendations for the design of under-deck cable-stayed bridges that are aimed to enable the accurate assessment of the response under the accidental breakage of stay cables, to enhance their capability to overcome this accidental situation, and to simplify the replacement of stay cables in the case that this is required.

\section{UNDER-DECK CABLE-STAYED BRIDGES WITH PRESTRESSED CONCRETE DECKS}

Two under-deck cable-stayed bridges have been designed: one with two struts and the other with multiple (fifteen) struts (Fig. 2). Both are single $80 \mathrm{~m}$ span bridges with prestressed concrete decks made up of 1-m deep voided slabs. The concrete characteristic strength in the deck is equal to 40 and $35 \mathrm{MPa}$ for the two-strut and multiple-strut bridges respectively. The under-deck cable-stayed system is made up of multiple strands (each with a cross section of $140 \mathrm{~mm}^{2}$ and with an ultimate tensile strength of $1860 \mathrm{MPa}$ ). The stay cables are self-anchored to the deck in the support sections over the abutments and are deviated by struts. The number of strands used is equal to 258 and 264 for the two-strut and multiple-strut bridge respectively. The stay-cable anchorages employed have conventional fatigue strengths, like those used for external prestressing.

The analysis of the structural response of both bridges under several permanent and variable actions (dead load, superimposed dead load, prestressing of the stay cables, internal prestressing, timedependent effects and traffic live load) and a set of design criteria for transient and persistent situations 
Cite this paper as: Ruiz-Teran AM, Aparicio AC, 2009, Response of under-deck cable-stayed bridges to the accidental breakage of stay cables, Engineering Structures, Vol:31, ISSN:0141-0296,

Pages:1425-1434 [DOI: 10.1016/j.engstruct.2009.02.027]

are published in [8].

\section{ANALYSIS OF THE ACCIDENTAL BREAKAGE OF STAY CABLES IN CABLE-}

\section{STAYED BRIDGES}

The breakage of stay cables is an accidental action that has to be considered in the design of cable-stayed bridges as part of the requirements of codes [14] and guidelines $[11,12,13,17]$. In general, the accidental situation caused by the sudden breakage of one stay cable must be overcome by the bridge without reaching any ultimate limit state. So far, the structural response due to the accidental loss of stay cables has been analysed in a very simple way, amplifying the results obtained from a static analysis by a DAF. The guidelines for cable-stayed bridges that recommend this method $[11,12,13]$ suggest values for DAFs less than or equal to 2 , since this was considered to be an upper bound for DAFs in the case of a sudden breakage of stay cables. Eurocode 1 Part 1.7 [15] states that 2 is an upper bound when the structure responds elastically and the load is suddenly applied. However, 2 is an upper bound only for single degree of freedom systems. The authors have recently proven, both analytically and numerically, that DAFs can be larger than $2[16]$ and, therefore, do not recommend these simple methods for cable-stayed structures.

In the case of the accidental breakage of a stay cable, the tension load in the breaking stay cable is gradually lost over the time that the breakage occurs (breakage time). Before the breakage (Fig. 3a), the stay cable is under a certain tension load $T_{0}$. After the complete breakage, the tension load in this stay cable is equal to zero. Therefore, the breakage load, a load with the same magnitude and opposite direction to $T_{0}$, is gradually applied over the breakage time through a time-dependent function $f(t)$ (Fig. 3b). Before the breakage, $f(t)$ is equal to zero and, when the stay cable is completely broken, $f(t)$ is equal to 1. $f(t)$ is a continuous function whose behaviour depends on the nature of the breakage. After the start of the breakage of a stay cable the structure is not in static equilibrium since the tension load in the breaking stay cable begins to decrease. Due to the lack of static equilibrium, accelerations are induced that cause the structure to oscillate about a new equilibrium position that is finally reached when the oscillations have been completely damped out. The breakage load is applied dynamically and, therefore, a dynamic analysis is required to obtain the real response. 
Cite this paper as: Ruiz-Teran AM, Aparicio AC, 2009, Response of under-deck cable-stayed bridges to the accidental breakage of stay cables, Engineering Structures, Vol:31, ISSN:0141-0296, Pages:1425-1434 [DOI: 10.1016/j.engstruct.2009.02.027]

In the pseudo-dynamic method, the breakage load is applied statically and the obtained response is multiplied by the $D A F$. This $D A F$ method (that is not recommended by the authors [16]) has been used in this paper in addition to the proper dynamic method in order to highlight the inappropriateness of its use.

\section{DYNAMIC RESPONSE OF AN UNDER-DECK CABLE-STAYED BRIDGE DUE TO ACCIDENTAL BREAKAGE OF STAY CABLES}

In this section, the dynamic response of under-deck cable-stayed bridges is analysed using the two example bridges introduced in Section 2. The dynamic response has been obtained by means of both direct time integration and modal superposition of the dynamical structural response in several linear 2D FE models developed with the commercial software SAP 2000 [18] using conventional techniques [19] with beam- and strut-type elements. In the two-strut bridge, 42 elements are used for modelling the deck, two for the struts, and three for the stay cables. In the multiple-strut bridge, 54 elements are used for modelling the deck, 15 for the struts, and 16 for the stay cables. The area and moment of inertia of the deck are equal to $7.394 \mathrm{~m}^{2}$ and $0.724 \mathrm{~m}^{4}$ respectively. The densities of prestressed concrete and steel have been taken to be respectively equal to 2500 and $7850 \mathrm{~kg} / \mathrm{m}^{3}$. A uniform additional mass due to the superimposed dead load equal to $4310 \mathrm{~kg} / \mathrm{m}$ has also been introduced in the model. The axial strains in the struts have been neglected. The Young's modulus for the stay cables, the $35 \mathrm{MPa}$ prestressed concrete and the $40 \mathrm{MPa}$ prestressed concrete are taken to equal 190000, 29779 and $30891 \mathrm{MPa}$ respectively. The struts have a pinned connection to the deck, as recommended in [8]. Both decks have one pinned and one roller support at each abutment. A damping ratio equal to $2 \%$ has been adopted in the FE models for all the vibrational modes, since similar values have been measured in two under-deck cable-stayed bridges (the Glacis Bridge [20] and the Takehana Bridge [21]). The first 15 vibrational modes have been considered.

In this paper, two parametric studies have been performed, one for each bridge introduced in Section 2 . The response of each bridge has been analysed by varying the following parameters:

- Breakage time, i.e., the length of time over which the breakage occurs;

- Type of breakage, i.e., the way in which the tension load is lost and thus the way in which the 
Cite this paper as: Ruiz-Teran AM, Aparicio AC, 2009, Response of under-deck cable-stayed bridges to the accidental breakage of stay cables, Engineering Structures, Vol:31, ISSN:0141-0296,

Pages:1425-1434 [DOI: 10.1016/j.engstruct.2009.02.027]

breakage load is applied;

- Load combinations. The breakage is developed in three different situations: (1) when there is no traffic live load over the deck; (2) when $50 \%$ of the total traffic live load is over the deck; and (3) when there is $100 \%$ of the traffic live load. The traffic load has been established according to the Spanish code [22], that prescribes a uniformly distributed load of $4 \mathrm{kN} / \mathrm{m}^{2}$ applied over the entire carriage-way width and one tandem system of $600 \mathrm{kN}$. The magnitude of the uniformly distributed load is 1.006 times that specified by Eurocode 1 Part $2\left(9 \mathrm{kN} / \mathrm{m}^{2}\right.$ over one $3 \mathrm{~m}$ wide lane and 2.5 $\mathrm{kN} / \mathrm{m}^{2}$ over the rest of the carriage way) [23], while the tandem system has exactly the same magnitude. The accidental combination prescribed by the Spanish code [22] considers 50\% of the traffic live load, while that prescribed by Eurocode [24] consider $40 \%$ for the uniformly distributed load and $75 \%$ for the tandem system;

- Deviators. Two types of deviators have been considered: (1) either deviators with clamps that prevent the cable sliding in all situations or deviators at which the stay cables are anchored (the response in both cases being the same); and (2) deviators without clamps, in which sliding under service conditions is prevented by the friction loads; and,

- Damage grade. Both bridges have been designed with five under-deck stay cables. The breakage of one, two, three, four and even five stay cables has been analysed.

The combinations of these parameters lead to the different scenarios considered in the parametric analyses.

Other parameters, such as the depth of the deck, the type of the transverse cross-section of the deck, the area of the stay cables, the eccentricity of the stay cables, the grade of presstressing, the links between different structural elements, etc, have not been considered in this paper, since they have previously been considered by the authors elsewhere $[7,8,9]$ and their design criteria are governed by transient and persistent situations. The authors have deliberately selected two bridges (those introduced in section 2) that satisfy all the required serviceability and ultimate limit states in both transient and persistent situations so that the conclusions drawn from this study have relevance from a practical point of view. Therefore, this study is focussed on all those parameters discussed earlier that 
Cite this paper as: Ruiz-Teran AM, Aparicio AC, 2009, Response of under-deck cable-stayed bridges to the accidental breakage of stay cables, Engineering Structures, Vol:31, ISSN:0141-0296,

Pages:1425-1434 [DOI: 10.1016/j.engstruct.2009.02.027]

relate to the response of the bridge under the breakage of stay cables.

\subsection{Breakage of stay cables in an under-deck cable-stayed bridge with two struts}

The accidental breakage of stay cables in the under-deck cable-stayed bridge with two struts is analysed in this subsection. Under permanent state, when the dead load, the superimposed dead load and the prestressing of the stay cables are applied, the axial load in the full section of the five stay cables is equal to $22.62 \mathrm{MN}$. This axial load increases to $28.37 \mathrm{MN}$ when the $100 \%$ of the traffic live load is applied.

\subsubsection{Sensitivity of the dynamic response to the breakage time and the type of application of the}

$\underline{\text { breakage load }}$

The influence on the dynamic response of both the breakage time and the breakage load application has been analysed. The breakage load is gradually applied in time, $t$, by means of a function defined by Eq. (1):

$$
F(t)=f\left(\frac{t}{T_{\text {breakage }}}\right) T_{0}
$$

where $f$ is the normalized shape-function used to apply the breakage load $T_{0}$ over a time interval equal to the breakage time $\left(T_{\text {breakage }}\right)$.

There is currently a lack of research regarding both the duration of the breakage time of stay cables due to accidental situations (such as collisions, explosions, etc.) and the way in which the tension load is lost (and consequently the way in which breakage load is applied), as these factors have not been relevant due to the use of the simple $D A F$ approach.

Due to this lack of information, the first step of the study was the consideration of whether or not the breakage time and the way in which the breakage load is applied have a significant influence on the dynamic response of this bridge type. Breakage times from 1/10000 to 10 times the fundamental period of the structure have been considered for the study. Seven different normalized shape-functions (defined and plotted in Fig. 4) have been used for applying the breakage load. Note that both the first $\left(f_{l}\right)$ and seventh $\left(f_{7}\right)$ normalized functions correspond to an instantaneous application of the breakage load. An initial parametric study has been conducted using both the breakage time and 
Cite this paper as: Ruiz-Teran AM, Aparicio AC, 2009, Response of under-deck cable-stayed bridges to the accidental breakage of stay cables, Engineering Structures, Vol:31, ISSN:0141-0296, Pages:1425-1434 [DOI: 10.1016/j.engstruct.2009.02.027]

the type of the normalized shape-function as parameters, analysing the dynamic response of this bridge under the breakage of one central under-deck stay cable when deviators have clamps. A total of 164 scenarios have been analysed in order to gauge the sensitivity to these two parameters. The ratio between the maximum dynamic sagging bending moment and the static sagging bending moment in the mid-span section (i.e., the $D A F$ related to sagging bending moments at mid-span) has been obtained and plotted in Fig. 5. From the obtained results, the following conclusions can be drawn:

- $\quad$ The maximum value of the $D A F$ and, therefore, the maximum dynamic response is obtained for a sudden application of the breakage load - i.e., for the first $\left(f_{1}\right)$ and the seventh $\left(f_{7}\right)$ normalized shape-functions;

- When the breakage time lasts less than one hundredth of the fundamental period of the structure, the maximum value of the $D A F$ is reached irrespective of the way in which the stay cable is broken and of the normalized shape-function that is used;

- For breakage times less than the fundamental period of the structure, the shorter the breakage time, the larger both the $D A F$ and the dynamic response;

- $\quad$ The smallest $D A F \mathrm{~s}$, and, therefore, the smallest dynamic response, for a certain breakage time is obtained when the breakage load is gradually applied in a linear manner with time - i.e. when the fourth $\left(f_{4}\right)$ normalized shape-function is used. The larger the average slope of the normalized shape-function, the more the function resembles the sudden application case - i.e., the first $\left(f_{l}\right)$ and the seventh $\left(f_{7}\right)$ normalized shape-functions - and, therefore, the higher the $D A F \mathrm{~s}$ and the dynamic response. Therefore, $D A F \mathrm{~s}$ based on the first $\left(f_{l}\right)$ normalized shape-function are larger than those based the second $\left(f_{2}\right)$, which are in turn larger than those based on the third $\left(f_{3}\right)$. Similarly, DAFs based on the seventh $\left(f_{7}\right)$ normalized shape-function are larger than those based on sixth $\left(f_{6}\right)$, which are in turn larger than those based on the fifth $\left(f_{5}\right)$;

- When the breaking load is gradually applied over a breakage time larger than the fundamental period of the structure, the dynamic response, and, therefore, the $D A F \mathrm{~s}$, are strongly influenced by the value of the ratio between the breakage time and the fundamental period of the structure after the loss of the stay cable (see Fig. 5 ; the $D A F$ s obtained using the fourth $\left(f_{4}\right)$ normalized shape- 
Cite this paper as: Ruiz-Teran AM, Aparicio AC, 2009, Response of under-deck cable-stayed bridges to the accidental breakage of stay cables, Engineering Structures, Vol:31, ISSN:0141-0296, Pages:1425-1434 [DOI: 10.1016/j.engstruct.2009.02.027]

function and, to a lesser extent, using the third $\left.\left(f_{3}\right)\right)$. When this ratio is close to an integer, the dynamic response, and, therefore, the $D A F$, is heavily reduced. On the other hand, when this ratio is close to the mean of two adjacent integers, both the dynamic response and the $D A F$ are largely amplified. This behaviour is due to a resonant effect. Fig. 6 has been sketched to clarify this phenomenon. When the breakage time is equal to the fundamental period of the bridge (see Fig 6a), the first half of the breakage load is applied in phase with the displacement of the structure (both have the same direction) whereas the second half of the breakage load is applied out of phase with the displacement of the structure, resulting in a reduction of the net motion. When the breakage time is equal to 1.5 times the fundamental period of the bridge (see Fig 6b), the first and last third of the breakage load is applied in phase with the displacement of the structure and only the second third is applied against the displacement of the structure. Consequently, the dynamic response is increased in comparison with the previous case in which the breakage time was equal to the fundamental period. The same effect explains the remaining peaks and valleys in Fig. 5 for larger breakage times; and,

- $\quad$ Even when the breakage load is linearly applied (for the fourth $\left(f_{4}\right)$ normalized shape-function), the $D A F$ s are larger than 2 over a wide range of breakage times shorter than 0.6 seconds. Breakage times smaller than this are likely and foreseeable and, therefore, $D A F$ s smaller than 2 are unconservative for this bridge type.

When the breakage time is negligible in comparison to the fundamental period of the structure (i.e., for breakage times smaller that one hundredth of the fundamental period of the structure), the shape of the function that defines the type of application of the breakage load (i.e., the way in which the stay cable load is lost) has no influence on the dynamic response. However, when the breakage time is of the order of the fundamental period of the structure, its shape has a large influence on it. For this bridge, the fundamental periods are longer than one second (1.25 seconds for the undamaged bridge and 1.28 seconds for the damaged bridge with one stay cable broken), whereas the accidental breakage might occur in hundredths or thousandths of a second. Consequently, for this bridge type in practical accidental situations of sudden breakage of stay cables, the function that defines the way in 
Cite this paper as: Ruiz-Teran AM, Aparicio AC, 2009, Response of under-deck cable-stayed bridges to the accidental breakage of stay cables, Engineering Structures, Vol:31, ISSN:0141-0296,

Pages:1425-1434 [DOI: 10.1016/j.engstruct.2009.02.027]

which the stay cable is broken has practically no influence on the response. Therefore, a sudden breakage load, using $f_{l}(t)$, that is also a conservative upper bound, has been considered for the rest of the analyses in this paper.

\subsubsection{Comparison of the envelopes of internal forces obtained from pseudo-dynamic and dynamic}

$\underline{\text { analysis }}$

Fig. 7 shows the bending moment envelopes along the deck, normalized with respect to the static bending moment at mid-span, due to the sudden breakage of one central under-deck stay cable (when deviators have clamps) obtained by both methods: the pseudo-dynamic analysis (with $D A F=2$ ) and a full dynamic analysis. From inspection of this figure it is clear that $D A F$ s (related to sagging bending moments) should take values larger than 2. Moreover, hogging bending moments that cannot be predicted with a pseudo-dynamic analysis using positive $D A F$ s occur all along the bridge. All of the areas with bending moments that are not conservatively predicted when using a pseudo-dynamic analysis with a $D A F$ equal to 2 have been shaded. The maximum sagging and hogging bending moments appear in the first moments after the breakage (see Fig. 8), when higher order dynamic modes with a negative projection over the static response have not yet been damped out [16]. These higher order dynamic modes that have a negative projection over the static response cause the occurrence of both positive $D A F$ s larger than 2 and negative $D A F$ s [16]. Therefore, positive and negative $D A F$ s would be required for estimating the maximum sagging and hogging bending moments. These $D A F$ s should take different values in each different section, as the shapes of the envelopes obtained from a pseudo-dynamic analysis are quite different to those obtained from a full dynamic analysis (see Fig. 7).

Shear and axial forces have also been analysed and the results are presented in Table 1. Six sections have been considered: S1 located in the deck $15 \mathrm{~m}$ from the abutments; S2 located in the deck, immediately adjacent to the connection to the strut, in the section between the abutment and the struts; S3 located in the deck, immediately adjacent to the connection to the strut, in the section between the two struts; S4 located in the deck, at mid-span; S5 located in the lateral stay cables; and S6 located in the central stay cables. The $D A F$ s related to axial forces are larger than those related to 
Cite this paper as: Ruiz-Teran AM, Aparicio AC, 2009, Response of under-deck cable-stayed bridges to the accidental breakage of stay cables, Engineering Structures, Vol:31, ISSN:0141-0296, Pages:1425-1434 [DOI: 10.1016/j.engstruct.2009.02.027]

shear forces, and those, in turn, are larger than those related to bending moments. Every section and every internal force require a different pair of $D A F \mathrm{~s}$ (one positive and one negative), and even in some cases these $D A F$ s tend to infinity as the magnitude of the static values tend to, or are, zero. Therefore, no $D A F$ can be defined as a conservative value recommendable for design in all the sections and for all the internal forces. Consequently, only a proper dynamic analysis should be used to accurately predict the structural response under a dynamic action such as the breakage of a stay cable and consequently the use of the $D A F$ method should be ceased henceforth.

\subsubsection{Comparison of the dynamic responses resulting from the breakage of a central and a lateral stay} cable

The sudden breakage of a lateral under-deck stay cable (in the section between the anchorage in the support section and the clamp at the deviator) has also been analysed. Fig. 9 represents the bending moment envelopes for the deck due to the accidental breakage of both a lateral and a central stay cable. Both envelopes are quite similar. The average difference between both of them is equal to $2 \%$, although in some particular sections the difference is higher $(21 \%$ in the section close to the left strut and $9 \%$ in the mid-span section).

\subsubsection{Influence of the type of deviator in the dynamic response following the breakage of stay cables}

If the deviators have no clamps, the stay cables are lost along their entire length (between their two anchorages in the support sections of the deck) in the case of their accidental breakage. This scenario has also been considered in Fig 9. This accidental breakage produces identical effects to the simultaneous breakage of three stay cables (one central and one lateral on each side) when deviators have clamps. Therefore, the values of the envelopes of the internal forces in this case almost triple those when the failure is concentrated in a central or lateral stay cable.

\subsubsection{Influence of the presence of traffic live load over the bridge when the breakage occurs}

The sudden accidental breakage of stay cables has been analysed considering the possibility that a certain percentage $(0 \%, 50 \%$ and $100 \%)$ of the traffic live load is also applied over the bridge when the failure of the stay cables occurs. The higher the traffic live load applied, the larger the axial load lost (i.e., the larger the breakage load), and the larger the internal forces due to the breakage of 
Cite this paper as: Ruiz-Teran AM, Aparicio AC, 2009, Response of under-deck cable-stayed bridges to the accidental breakage of stay cables, Engineering Structures, Vol:31, ISSN:0141-0296,

Pages:1425-1434 [DOI: 10.1016/j.engstruct.2009.02.027]

the stay cables.

\subsubsection{Capacity to overcome the accidental situation when several stay cables are broken}

The paths traced over time by the design values of the internal forces (in the sections defined previously) after the breakage of two stay cables when $50 \%$ of the traffic live load is applied are presented in Fig 10, for deviators with (case a) and without (case b) clamps. The design values in the deck have been plotted for two different load combinations: one (in black) maximizing the sagging bending moments and one (in grey) maximizing the hogging bending moments. The resistances have also been represented. Regardless of the deviator type, this bridge has more than enough capacity to overcome this accidental scenario.

The paths traced out over time by the stresses in the central stay cables after the breakage of one, two, and three stay cables have been plotted in Fig. 11 for two different levels of traffic live load (0\% and 100\%) and two different deviator types. The axial strength (1860 MPa) of the stay cables has also been included. The bridge has enough capacity to overcome the breakage of two stay cables, regardless of the percentage of traffic live load applied during the breakage and the anchorage type. However, the bridge cannot overcome the breakage of three stay cables even if no traffic live load is applied, since the stay cables have insufficient tensile capacity to resist the design values.

The use of deviators without clamps significantly increases the magnitudes of the design bending moments (see Fig. 10b), as explained previously in section 4.1.4. When three stay cables are broken and this deviator type is used, the failure also occurs due to the fact that the design sagging bending moments in the deck are larger than the bending resistance (in addition to the aforementioned fact that the stay cables have insufficient axial resistance). Using this deviator type, the maximum stresses in the stay cables are amplified by approximately a $10 \%$ in comparison to those when using deviators with clamps.

\subsection{Breakage of stay cables in an under-deck cable-stayed bridge with multiple struts}

The accidental breakage of stay cables in the under-deck cable-stayed bridge with multiple struts is analysed in this subsection. In permanent state, when the dead load, the superimposed dead load and the prestressing of the stay cables are applied, the axial load in the full section of five stay 
Cite this paper as: Ruiz-Teran AM, Aparicio AC, 2009, Response of under-deck cable-stayed bridges to the accidental breakage of stay cables, Engineering Structures, Vol:31, ISSN:0141-0296,

Pages:1425-1434 [DOI: 10.1016/j.engstruct.2009.02.027]

cables is equal to $22.86 \mathrm{MN}$. This axial load increases to $28.77 \mathrm{MN}$ when $100 \%$ of the traffic live load is applied.

In under-deck cable-stayed bridges with multiple struts, the use of clamps at all of the deviators significantly reduces the response under the accidental breakage of stay cables but leads to an increase in the cost that may not be justified. Due to this, the only deviator type that has been considered here is that without clamps. In this scenario, the entire length of the cable is lost when the breakage occurs. Fig. 12 is the replication of Fig. 7 for this bridge type. All the conclusions inferred from Fig. 7 are also applicable to Fig. 12.

The results obtained from a similar parametric study to that previously described for a twostrut under-deck cable-stayed bridge show that this bridge is also able to overcome the breakage of two out of five stay cables, regardless of the percentage of the traffic live load that is applied during the breakage (Fig 13).

Both bridges, with two and multiple struts, have a similar behaviour under the accidental breakage of stay cables. Consequently, the conclusions drawn earlier regarding the behaviour under the accidental breakage of stay cables can be generically extended to the entire bridge type, regardless of the number of struts used.

\section{DESIGN RECOMMENDATIONS}

Based on this study, the following set of design criteria related to the assessment of the dynamic response under the accidental breakage of stay cables and the characteristics of the deviator recommended for under-deck cable-stayed bridges is established:

- The response of this bridge type under the accidental breakage of stay cables must be analysed by means of a full dynamic analysis and not by the $D A F$ method currently recommended in several guidelines [11,12,13] and proposed implicitly by Eurocode 3 Part 1.11 [14] and explicitly by Eurocode 1 Part 1.7 [15];

- If the design breakage time is equal to or smaller than one percent of the fundamental period of the structure (after the breakage), the way in which the stay cable breaks does not affect the dynamic response and, therefore, the simplest case of a sudden breakage can be assumed. On the other 
Cite this paper as: Ruiz-Teran AM, Aparicio AC, 2009, Response of under-deck cable-stayed bridges to the accidental breakage of stay cables, Engineering Structures, Vol:31, ISSN:0141-0296, Pages:1425-1434 [DOI: 10.1016/j.engstruct.2009.02.027]

hand, if the design breakage time is larger than this value, the case of a sudden breakage can be considered as a conservative upper bound, although the consideration of the way in which the cable breaks, through a normalized shape function appropriate for design, can significantly reduce the dynamic response obtained (especially when the breakage time is larger than the fundamental period of the structure). Further investigations are required in order to identify the most appropriate breakage functions for design;

- The dynamic breakage load that has to be considered in the dynamic analysis depends on the load that is carried by the broken stay cables before the breakage (and, therefore, on the load combination before the breakage) and also on the deviator type used. If the deviators have no clamps (Fig. 14 a), the broken cable is completely lost along its entire length, whereas, if the deviators have either clamps or anchorages that are able to anchor the broken cables between the sections where they have not been damaged (Fig. $14 \mathrm{c}$ and d), the broken cables are only lost between deviators;

- Deviators with clamps capable of anchoring the broken stay cables after the breakage (Fig. $14 \mathrm{c}$ and d) enhance the capacity of the structure to overcome the accidental situation of breakage of stay cables but increase the price of the structure. These clamps must be designed to resist a clamping load equal to the maximum dynamic tension in the broken stay cable in those sections not affected by the breakage;

- $\quad$ The design of deviators with guide-tubes (Fig 14 b) simplifies the threading of the stay cables; and,

- The use of extra guide-tubes (Fig. 14 b) that remain empty during the service-life of the bridge is advisable, allowing: (1) the substitution of a stay cable without closing the upper and lower roads; and (2) the reinforcement of the structure if required.

\section{CONCLUSIONS}

Under-deck cable-stayed bridges are an appropriate structural solution for highway overpasses as long as there is enough vertical clearance to position the under-deck stay cables. In this paper the doubts that have emerged over the possibility of collapse of this type of bridge due to the breakage of 
Cite this paper as: Ruiz-Teran AM, Aparicio AC, 2009, Response of under-deck cable-stayed bridges to the accidental breakage of stay cables, Engineering Structures, Vol:31, ISSN:0141-0296, Pages:1425-1434 [DOI: 10.1016/j.engstruct.2009.02.027]

stay cables following an accidental collision have been shown to be unfounded. The example bridges considered herein are able to overcome the accidental breakage of two out of five of the stay cables, even when $100 \%$ of the traffic live load is applied over the bridge. This accidental scenario is far more severe than that demanded by codes (breakage of one stay when $50 \%$ of the traffic live load is applied). Furthermore, if the unlikely scenario of the sudden breakage of stay cables occurs, the repair of the structure could be carried out in a simpler, quicker and cheaper way than in the case of a conventional structure, and even without affecting the traffic, as long as this circumstance had been catered for during the design stage. A set of design criteria related to the assessment of the dynamic response under the accidental breakage of stay cables and the recommended characteristics of the deviators for under-deck cable-stayed bridges (in order to enhance their capability to overcome this accidental situation and also to simplify the replacement of stay cables in the case that it is required) has been established. In addition, the inappropriateness of the $D A F$ approach for analysing the response due to the breakage of stay cables has been highlighted and a full dynamic analysis is strongly recommended in its place.

\section{REFERENCES}

[1] Leonhardt F. Bridges, Ponts, Puentes, Lausanne: Presses polytechniques romandes, 1982. (in French and Spanish).

[2] Holgate A. The art of structural engineering - The work of Jörg Schlaich and his team, Stuttgart: Edition Alex Menges, 1997.

[3] Virlogeux M, Bouchon E, Lefevre J, Resplendino J, Crocherie A, Ageron C, Bourjot A, Clement M, Million P, Gudefin C, Valence M. A Prestressed concrete slab supported from below: The Truc de la Fare Bridge. Proceedings of the 12th FIP (International Federation for Structural Concrete) Congress, Washington, 1994.

[4] Gonzalez A. Transverse axis of Catalonia — Section: Calldetenes-Sant Juliá de Vilatorta-Sant Sadurni d'Osormort. Revista de Obras Públicas 1997; 3364: 61-66 (in Spanish). 
Cite this paper as: Ruiz-Teran AM, Aparicio AC, 2009, Response of under-deck cable-stayed bridges to the accidental breakage of stay cables, Engineering Structures, Vol:31, ISSN:0141-0296,

Pages:1425-1434 [DOI: 10.1016/j.engstruct.2009.02.027]

[5] Forno JY, Cremer JM. Steel bridges and composite bridges designed in Greisch Office.

Proceedings of the $3^{\text {rd }}$ International on composite bridges. State-of-the-art of their technology and analysis methods, Madrid, 2001; 721-742 (in Spanish).

[6] Ruiz-Teran AM, Aparicio AC. Two new types of bridges: under-deck cable-stayed bridges and combined cable-stayed bridges — the state of the art. Canadian Journal of Civil Engineering 2007; 34(8): 1003-1015

[7] Ruiz-Teran AM, Aparicio AC. Parameters governing the response of under-deck cable-stayed bridges. Canadian Journal of Civil Engineering 2007; 34(8): 1016-1024.

[8] Ruiz-Teran AM, Aparicio AC. Structural behaviour and design criteria of under-deck cablestayed bridges and combined cable-stayed bridges. Part 1: Single span bridges. Canadian Journal of Civil Engineering 2008; 35(9): 938-950.

[9] Ruiz-Teran AM, Aparicio AC. Structural behaviour and design criteria of under-deck cablestayed bridges and combined cable-stayed bridges. Part 2: Multispan bridges. Canadian Journal of Civil Engineering 2008; 35(9): 951-962.

[10] Schlaich J, Schober H. Highway overpass in Kirchheim (Steg über die Autobahn bei Kirchheim). Beton und Stahlbetonbau, 1994; 89(2): 40-44 (in German).

[11] Recommendations for Stay Cable Design — Testing and Installation, Phoenix, Arizona: PostTensioning Institute (PTI), 2007.

[12] Haubans - Recomendations de la commission interministérielle de la précontrainte, Bagneux Cedex, France: Service d'Études Techniques des Routes et Autoroutes (SETRA), 2001 (in French).

[13] Manual of stay cables, Madrid, Spain: Asociación Científico-Técnica del Hormigón Estructural (ACHE), 2007 (in Spanish).

[14] Eurocode 3: Design of steel structures. Part 1.11: Design of structures with tension components, Brussels, Belgium: European committee for standardization (CEN), 2006.

[15] Eurocode 1: Actions on structures. Part 1.7: Accidental actions, Brussels, Belgium: European committee for standardization (CEN), 2006. 
Cite this paper as: Ruiz-Teran AM, Aparicio AC, 2009, Response of under-deck cable-stayed bridges to the accidental breakage of stay cables, Engineering Structures, Vol:31, ISSN:0141-0296,

Pages:1425-1434 [DOI: 10.1016/j.engstruct.2009.02.027]

[16] Ruiz-Teran AM, Aparicio AC. Dynamic amplification factors in cable-stayed structures. Journal of Sound and Vibration 2007; 300(1-2):197-216.

[17] FIB Bulletin No. 30. Acceptance of stay cable systems using prestressing steels, Lausanne, Switzerland: Federation International du beton, 2005.

[18] SAP 2000. Integrated finite element analysis and design of structures, Berkeley, California: Computers and Structures, Inc, 2008.

[19] Hambly EC. Bridge deck behaviour, London, UK: Chapman and Hall, 1991.

[20] Schlaich M, Werwigk M. The Glacis Bridge in Ingolstadt, Germany. Design and Construction. Proceedings of the IABSE (International Association of Bridge and Structural Engineering) Conference. Cable-Supported Bridges. Challenging Technical Limits, Seoul, Japan, 2001.

[21] Nakagawa T, Okada T, Hamazaki Y, Okada N, Mochiduki H, Nagai M. Structural Characteristics of a Cable-Trussed Bridge. Proceedings of the IABSE (International Association of Bridge and Structural Engineering) Conference. Cable-Supported Bridges. Challenging Technical Limits, Seoul, Japan, 2001.

[22] IAP. Code of actions to be considered in the design of road bridges, Madrid, Spain: Ministerio de Fomento, 1998. (In Spanish).

[23] Eurocode 1: Actions on structures. Part 2: Traffic loads on bridges, Brussels, Belgium: European committee for standardization (CEN), 2003

[24] Eurocode: Basis of Structural design, Brussels, Belgium: European committee for standardization (CEN), 2005 
Cite this paper as: Ruiz-Teran AM, Aparicio AC, 2009, Response of under-deck cable-stayed bridges to the accidental breakage of stay cables, Engineering Structures, Vol:31, ISSN:0141-0296,

Pages:1425-1434 [DOI: 10.1016/j.engstruct.2009.02.027]

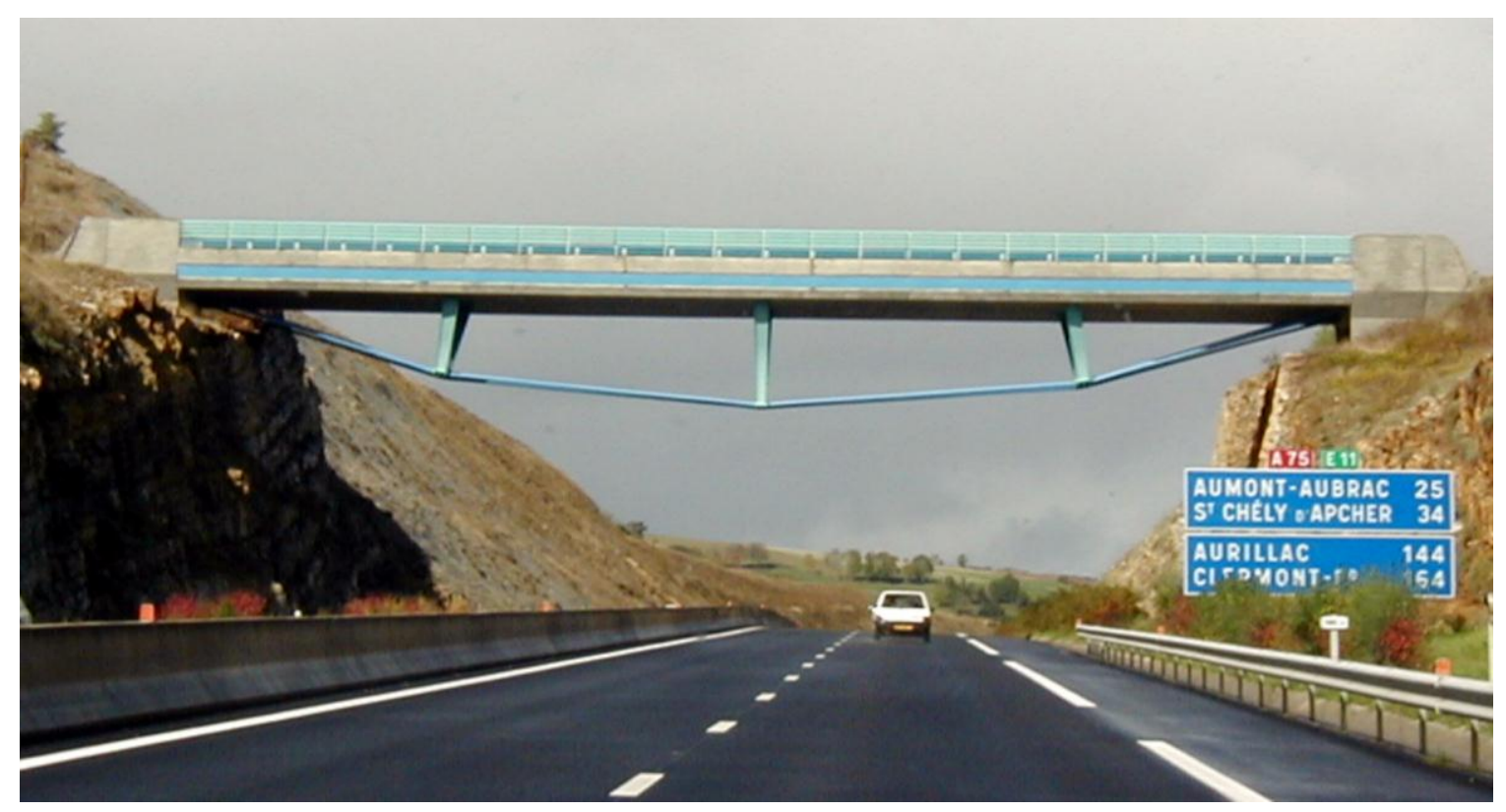

Fig. 1. Truc de la Fare overpass, designed by Michael Virlogeux (courtesy of Nicolas Janberg, www.structurae.de) 
Cite this paper as: Ruiz-Teran AM, Aparicio AC, 2009, Response of under-deck cable-stayed bridges to the accidental breakage of stay cables, Engineering Structures, Vol:31, ISSN:0141-0296,

Pages:1425-1434 [DOI: 10.1016/j.engstruct.2009.02.027]

a)
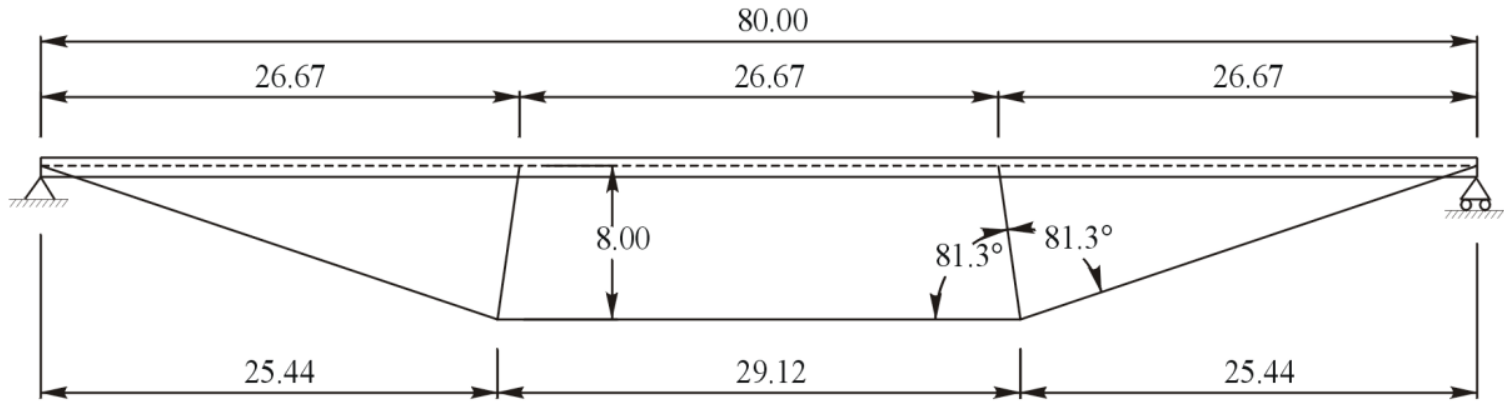

80.00

b)

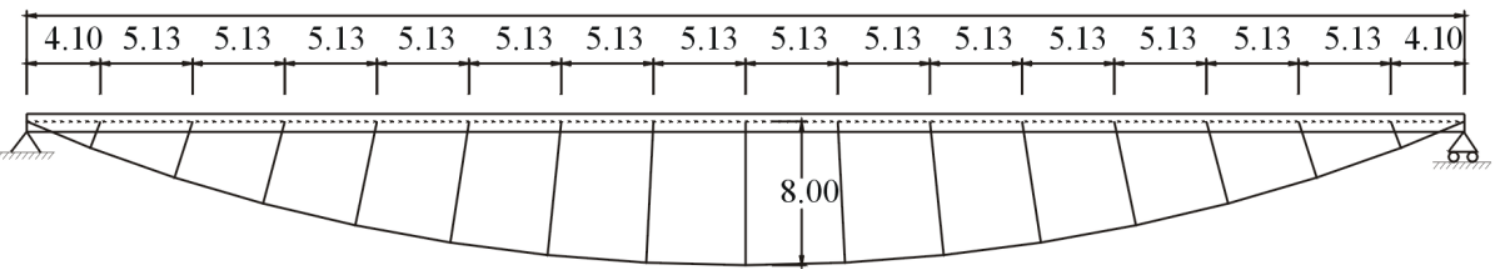

c)

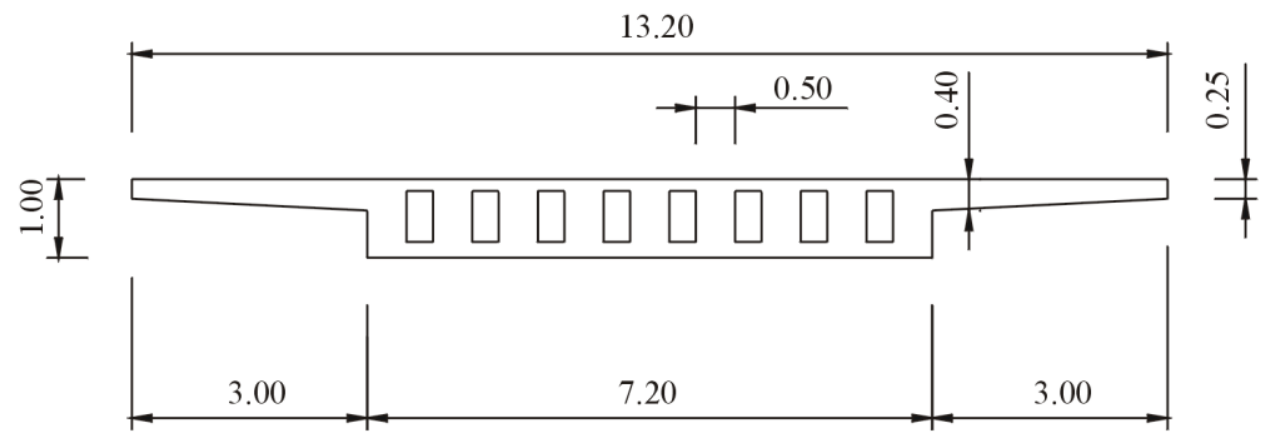

d)

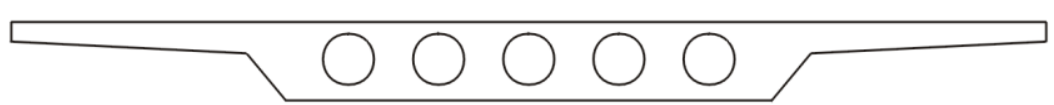

Fig. 2. Under-deck cable-stayed bridges: a) elevation with 2 struts, b) elevation with multiple struts, c) calculation cross-section in both cases, d) real cross-section in both cases.

Values in units of $\mathrm{m}$. 
Cite this paper as: Ruiz-Teran AM, Aparicio AC, 2009, Response of under-deck cable-stayed bridges to the accidental breakage of stay cables, Engineering Structures, Vol:31, ISSN:0141-0296,

Pages:1425-1434 [DOI: 10.1016/j.engstruct.2009.02.027]

a)

LOAD STATE 1 (Permanent + traffic live loads applied)

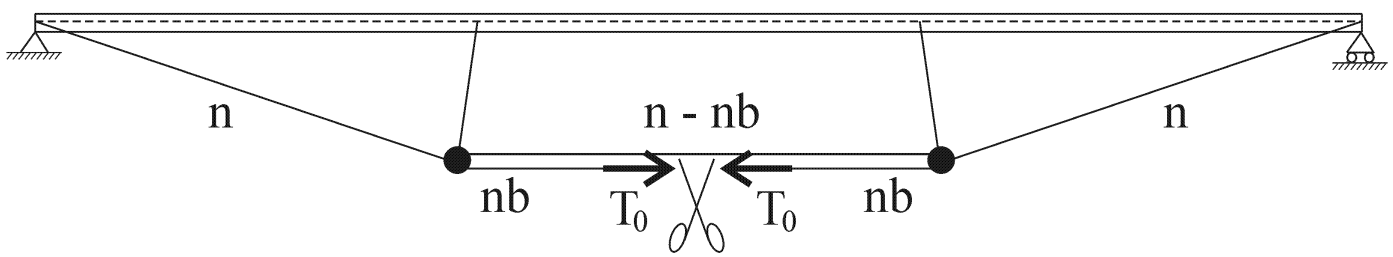

b)

LOAD STATE 1 (Permanent + traffic live loads applied)
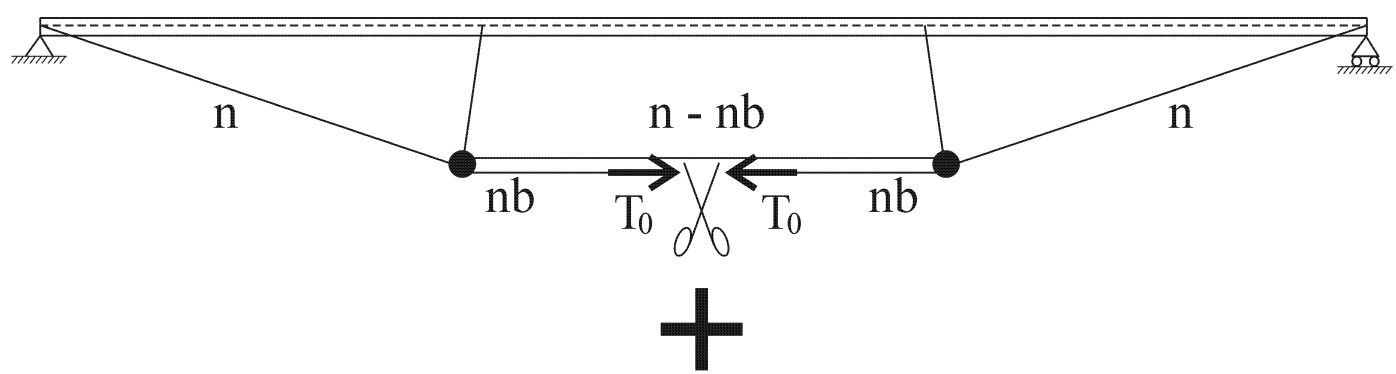

LOAD STATE 2 (Application of the Breakage load during the Breakage time)

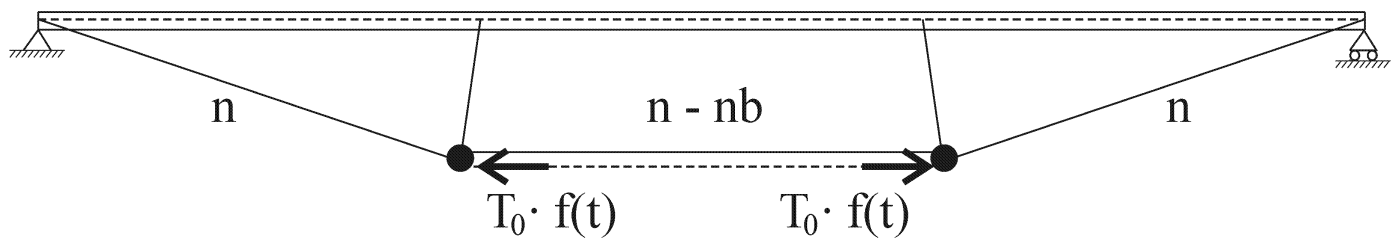

- Deviators with anchorages

$\mathrm{W}_{\text {Stay cable that is going to be broken }}$

$\mathrm{n}$ : total number of stay cables nb: number of broken stay cables

Fig. 3. Breakage of a stay cable and dynamic application of the breakage load. Schemes a) before and

b) after the breakage of the stay cable. 
Cite this paper as: Ruiz-Teran AM, Aparicio AC, 2009, Response of under-deck cable-stayed bridges to the accidental breakage of stay cables, Engineering Structures, Vol:31, ISSN:0141-0296,

Pages:1425-1434 [DOI: 10.1016/j.engstruct.2009.02.027]

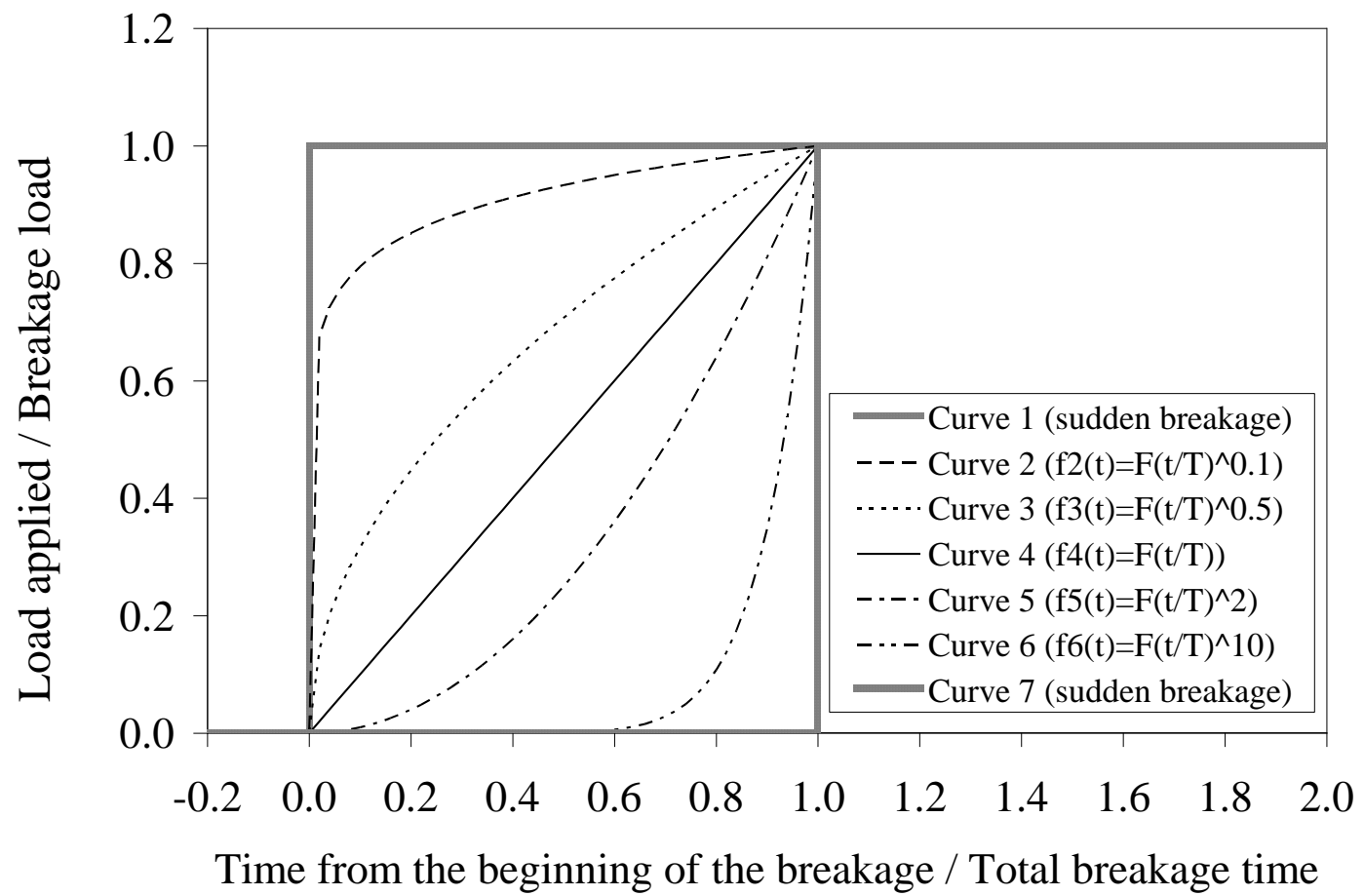

Fig. 4. Shape of the seven different normalized shape functions $f(t)$ considered for the application of the breakage load over the breakage time $(\mathrm{T})$ 
Cite this paper as: Ruiz-Teran AM, Aparicio AC, 2009, Response of under-deck cable-stayed bridges to the accidental breakage of stay cables, Engineering Structures, Vol:31, ISSN:0141-0296,

Pages:1425-1434 [DOI: 10.1016/j.engstruct.2009.02.027]

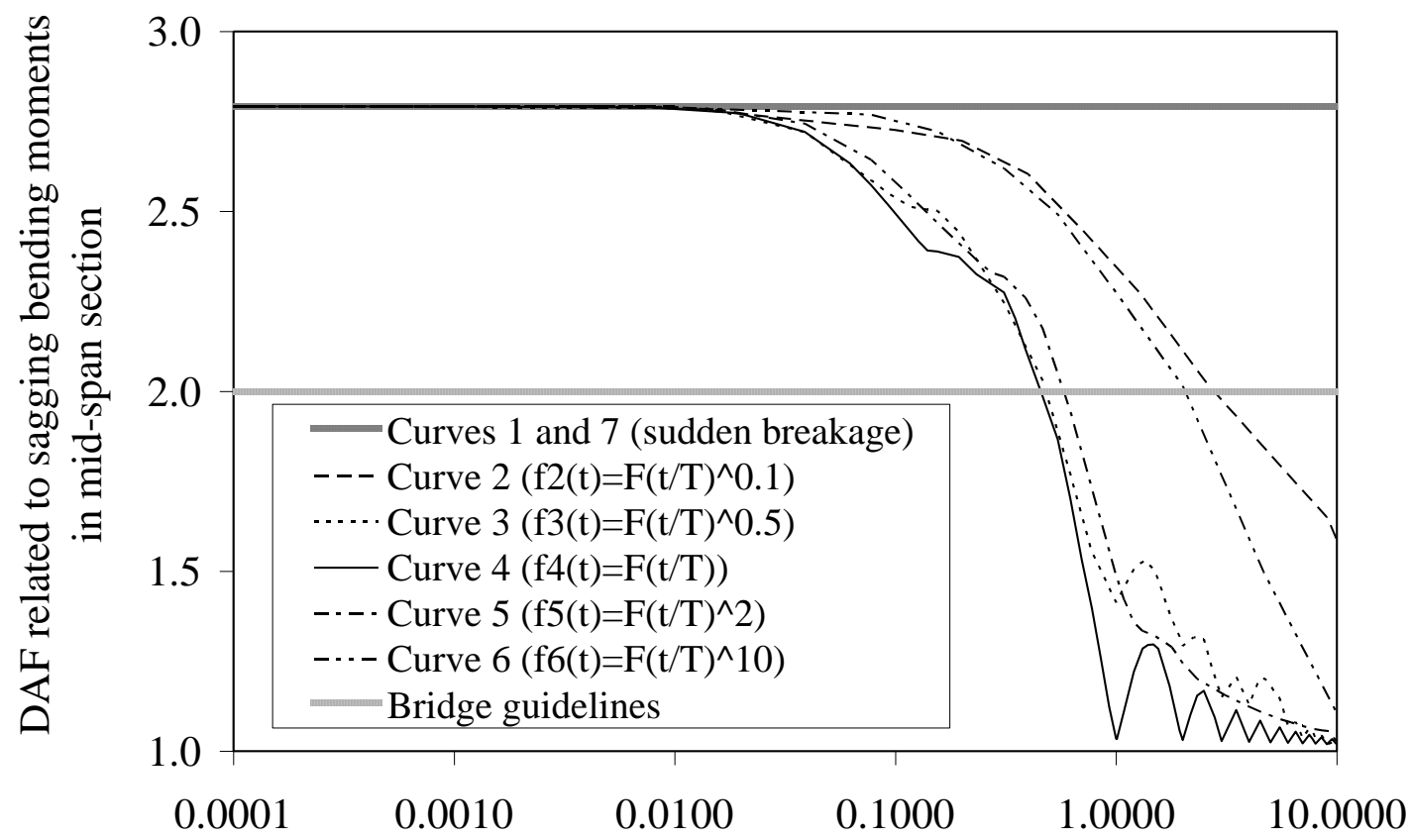

Breakage time of the stay cable / fundamental period of the structure

Fig. 5. Dynamic amplification factor $(D A F)$ related to sagging bending moments in the mid-span section obtained using different normalized shape functions $f(t)$. Case: breakage of one stay cable in the 2 strut-bridge when the deviators have clamps and no traffic load is applied. 
Cite this paper as: Ruiz-Teran AM, Aparicio AC, 2009, Response of under-deck cable-stayed bridges to the accidental breakage of stay cables, Engineering Structures, Vol:31, ISSN:0141-0296, Pages:1425-1434 [DOI: 10.1016/j.engstruct.2009.02.027]

a)

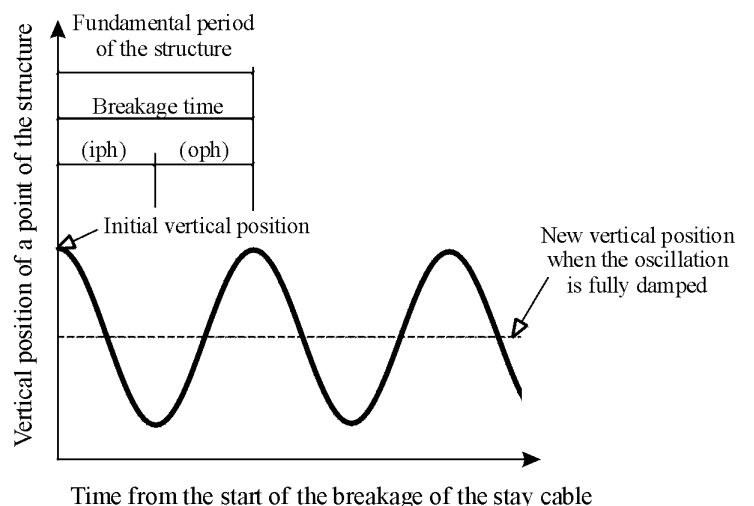

b)

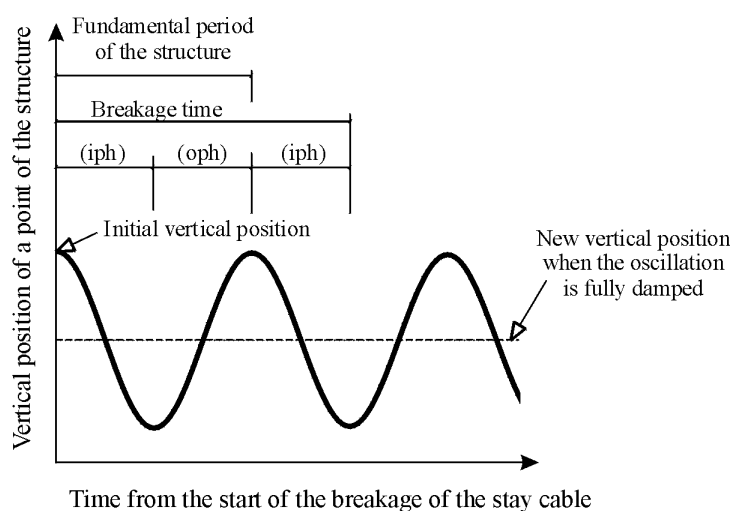

(iph): The structure is moving downwards and the breakage load causes downward movements. Therefore, they are in phase (oph): The structure is moving upwards and the breakage load causes downward movements. Therefore, they are out of phase

Fig. 6. Simple schemes showing the relation - in phase (iph) or out of phase (oph) - between the dynamic vibration of the structure and the deflections due to the breakage load. a) The breakage time is equal to the fundamental period of the structure; b) the breakage time is 1.5 times the fundamental period of the structure. 
Cite this paper as: Ruiz-Teran AM, Aparicio AC, 2009, Response of under-deck cable-stayed bridges to the accidental breakage of stay cables, Engineering Structures, Vol:31, ISSN:0141-0296,

Pages:1425-1434 [DOI: 10.1016/j.engstruct.2009.02.027]
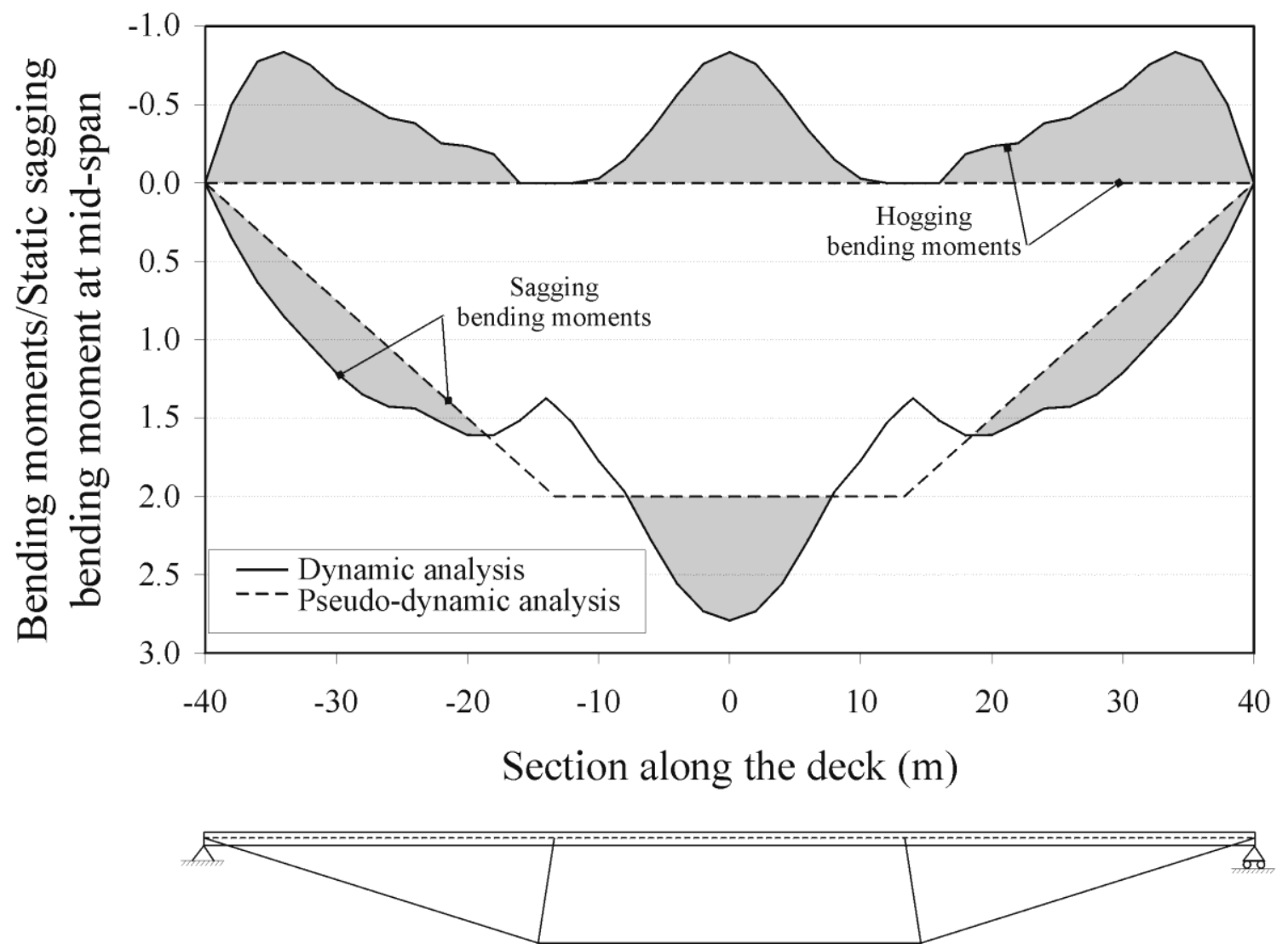

Fig. 7. Comparison between the bending moment envelopes in the deck obtained with dynamic and pseudo-dynamic analysis. Case: breakage of one stay cable in the 2-strut bridge when the deviators have clamps and no traffic load is applied. 
Cite this paper as: Ruiz-Teran AM, Aparicio AC, 2009, Response of under-deck cable-stayed bridges to the accidental breakage of stay cables, Engineering Structures, Vol:31, ISSN:0141-0296,

Pages:1425-1434 [DOI: 10.1016/j.engstruct.2009.02.027]

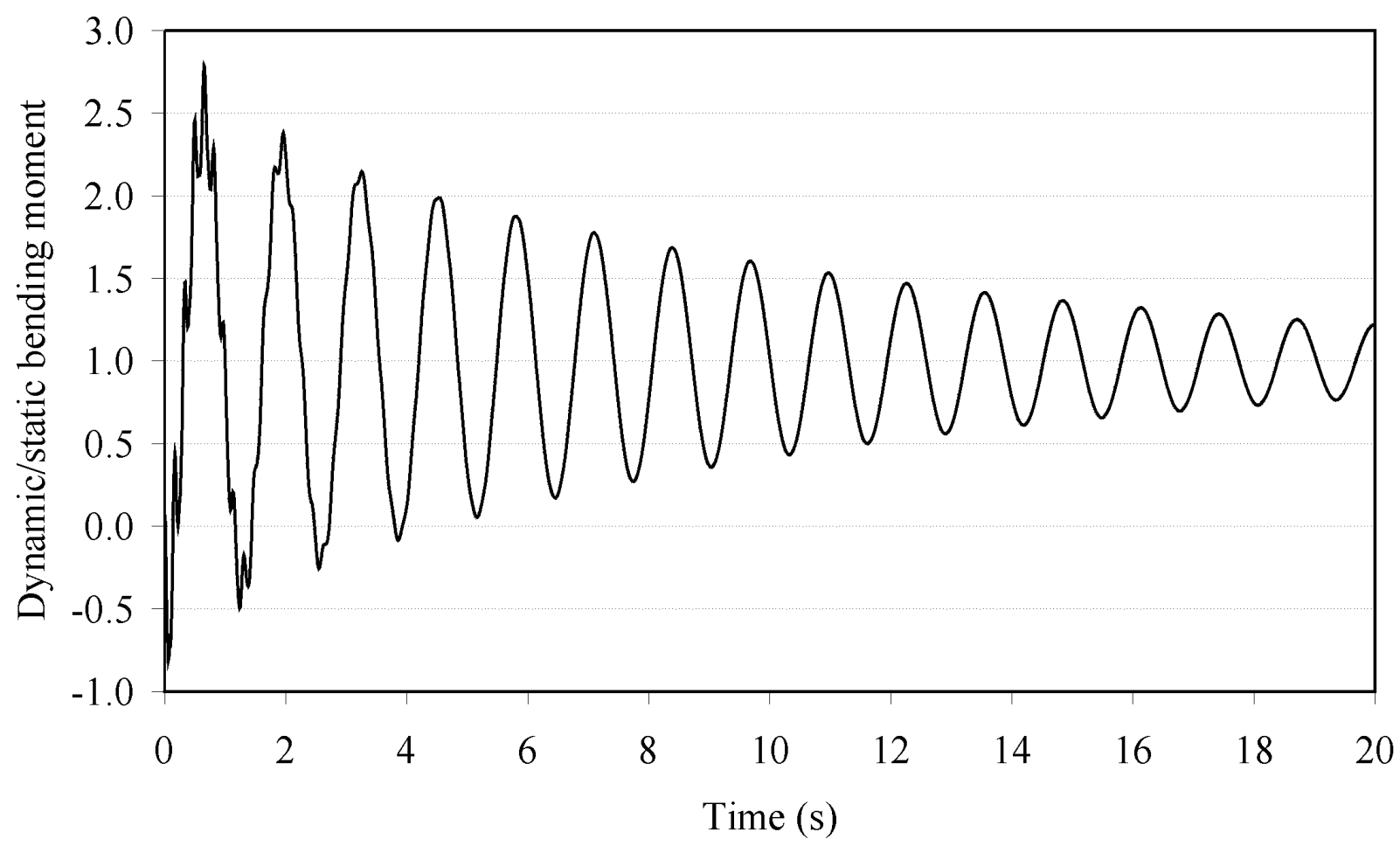

Fig. 8. Ratio between dynamic and static bending moments in the mid-span section versus time. Case: breakage of one stay cable in the 2 strut-bridge when the deviators have clamps and no traffic load is applied. 
Cite this paper as: Ruiz-Teran AM, Aparicio AC, 2009, Response of under-deck cable-stayed bridges to the accidental breakage of stay cables, Engineering Structures, Vol:31, ISSN:0141-0296,

Pages:1425-1434 [DOI: 10.1016/j.engstruct.2009.02.027]
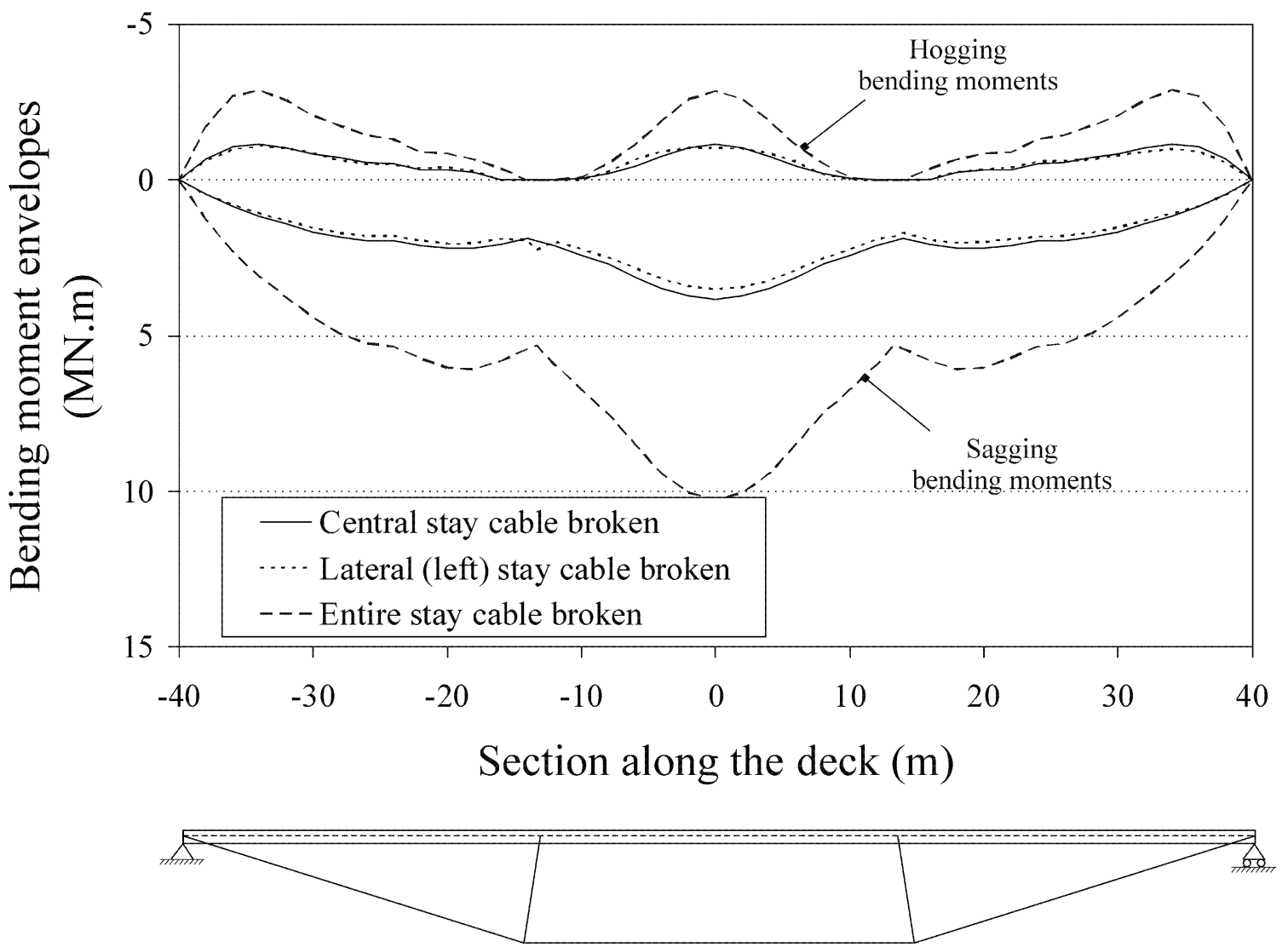

Fig. 9. Comparison between the dynamic bending moment envelopes in the deck due to the accidental breakage of one lateral (left) stay cable (deviators with clamps), one central stay cable (deviators with clamps) and one entire stay cable (deviators without clamps). 
Cite this paper as: Ruiz-Teran AM, Aparicio AC, 2009, Response of under-deck cable-stayed bridges to the accidental breakage of stay cables, Engineering Structures, Vol:31, ISSN:0141-0296,

Pages:1425-1434 [DOI: 10.1016/j.engstruct.2009.02.027]

a)
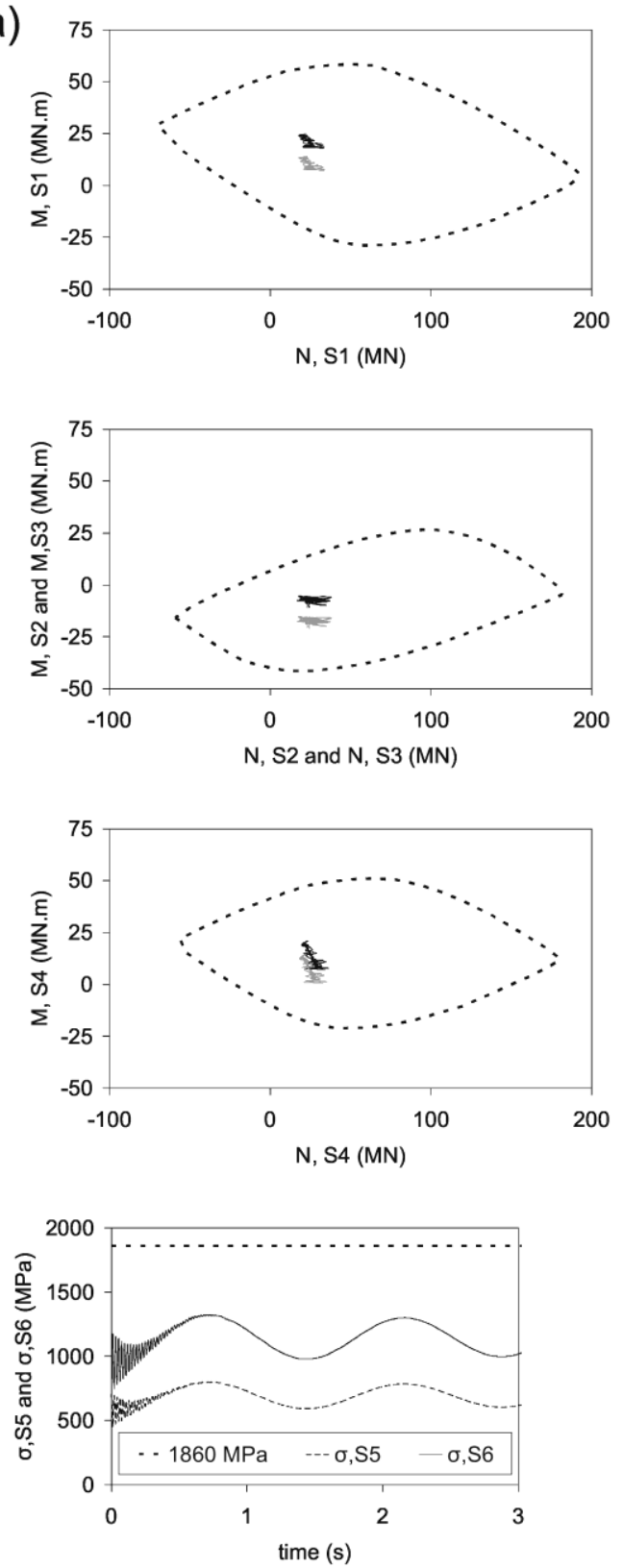

b)
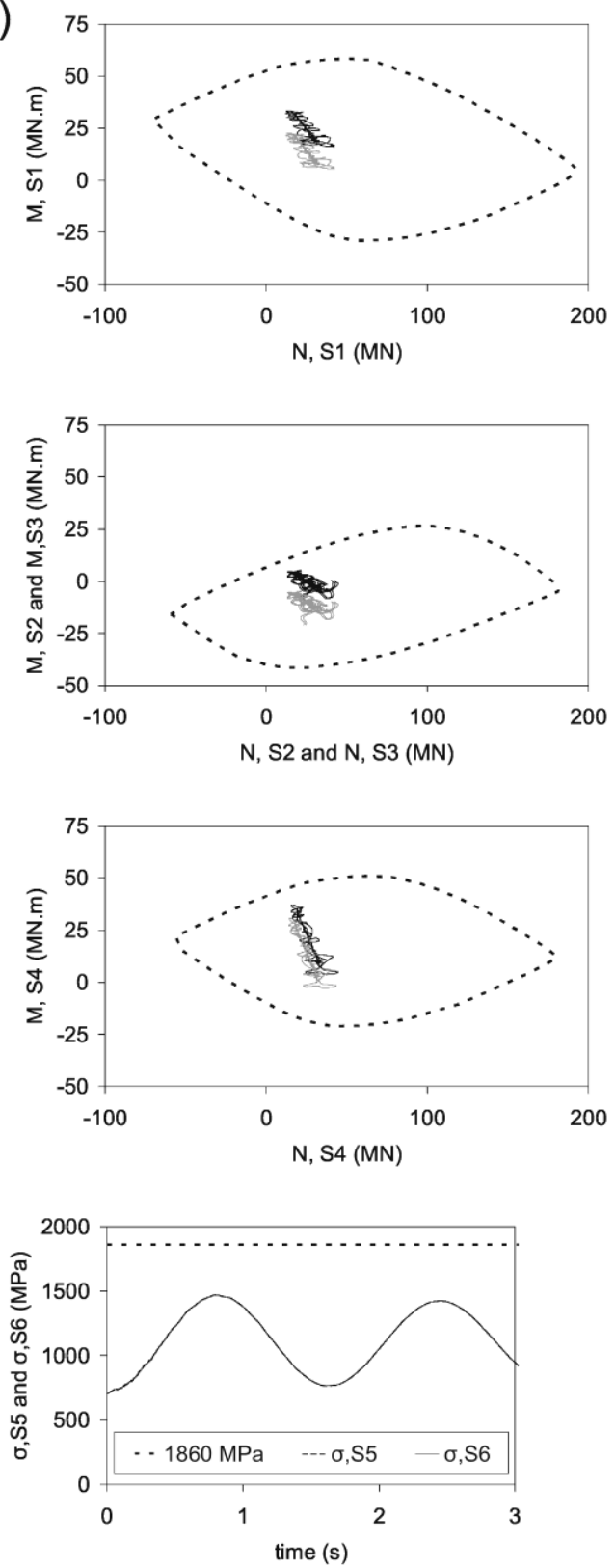

Fig. 10. Diagrams representing both the path traced over time by the design values (bending moments $(\mathrm{M})$, axial loads $(\mathrm{N})$ and stresses $(\sigma))$ and the corresponding resistances in sections $\mathrm{S} 1, \mathrm{~S} 2, \mathrm{~S} 3$ and $\mathrm{S} 4$ of the deck and sections S5 and S6 of the stay cables for the two-strut bridge due to the breakage of 2 stay cables when $50 \%$ of the traffic live load is applied. Deviators with (a) and without (b) clamps. 
Cite this paper as: Ruiz-Teran AM, Aparicio AC, 2009, Response of under-deck cable-stayed bridges to the accidental breakage of stay cables, Engineering Structures, Vol:31, ISSN:0141-0296, Pages:1425-1434 [DOI: 10.1016/j.engstruct.2009.02.027]

a)
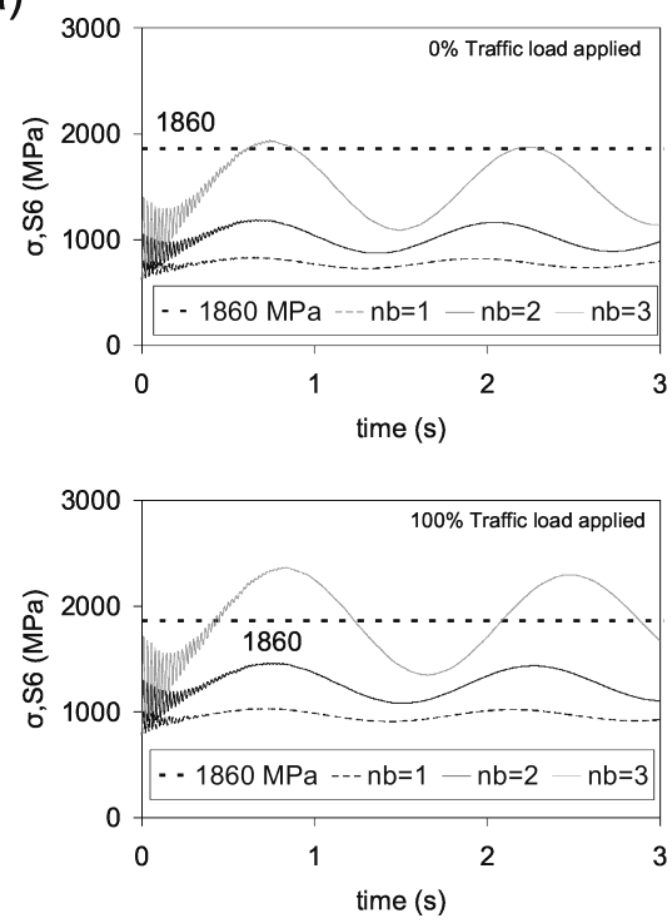

b)
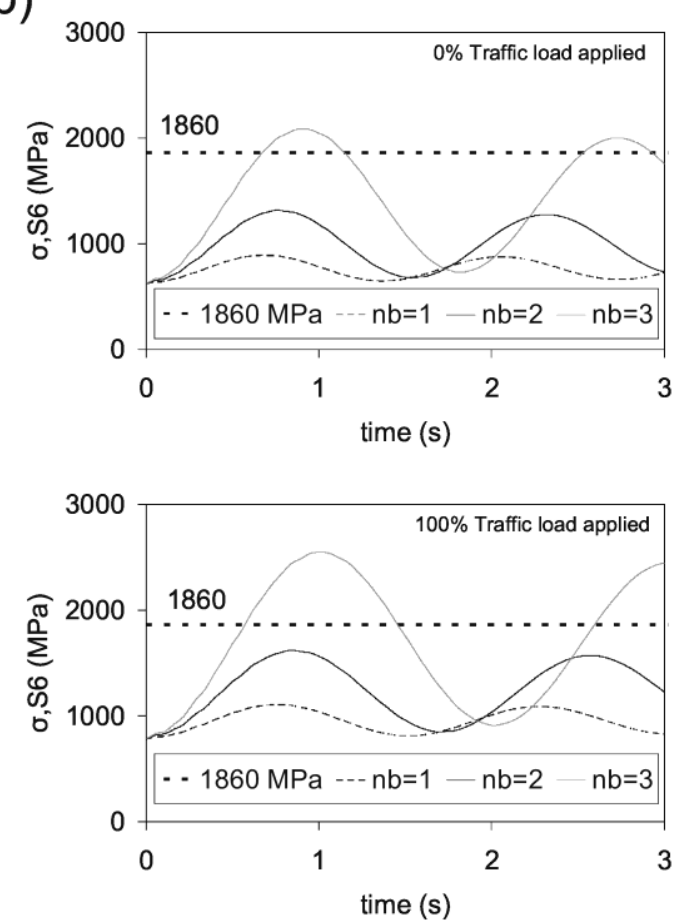

Fig. 11. Diagrams representing the design stresses in the central stay cables (section S6) $(\sigma)$ against time due to the breakage of a certain number of stay cables $(n b)$ in the 2-strut bridge, when $0 \%$ and $100 \%$ of the traffic live load is applied, and the resistances of the stay cables. Deviators with (a) and without (b) clamps. 
Cite this paper as: Ruiz-Teran AM, Aparicio AC, 2009, Response of under-deck cable-stayed bridges to the accidental breakage of stay cables, Engineering Structures, Vol:31, ISSN:0141-0296,

Pages:1425-1434 [DOI: 10.1016/j.engstruct.2009.02.027]
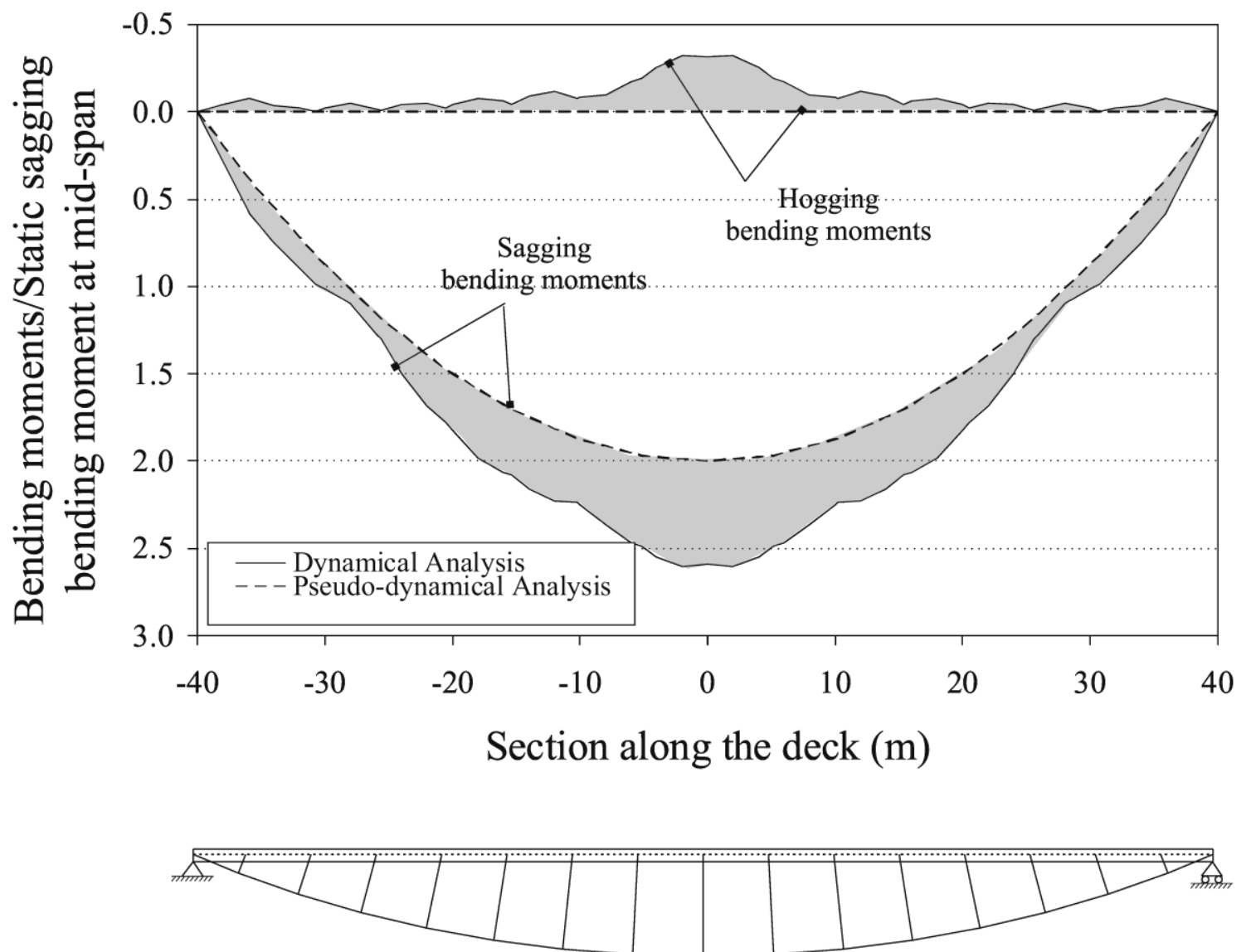

Fig. 12. Comparison between the bending moment envelopes in the deck obtained with dynamic and pseudo-dynamic analysis. Case: breakage of one stay cable in the multiple-strut bridge when deviators have no clamps and no traffic load is applied. 
Cite this paper as: Ruiz-Teran AM, Aparicio AC, 2009, Response of under-deck cable-stayed bridges to the accidental breakage of stay cables, Engineering Structures, Vol:31, ISSN:0141-0296,

Pages:1425-1434 [DOI: 10.1016/j.engstruct.2009.02.027]
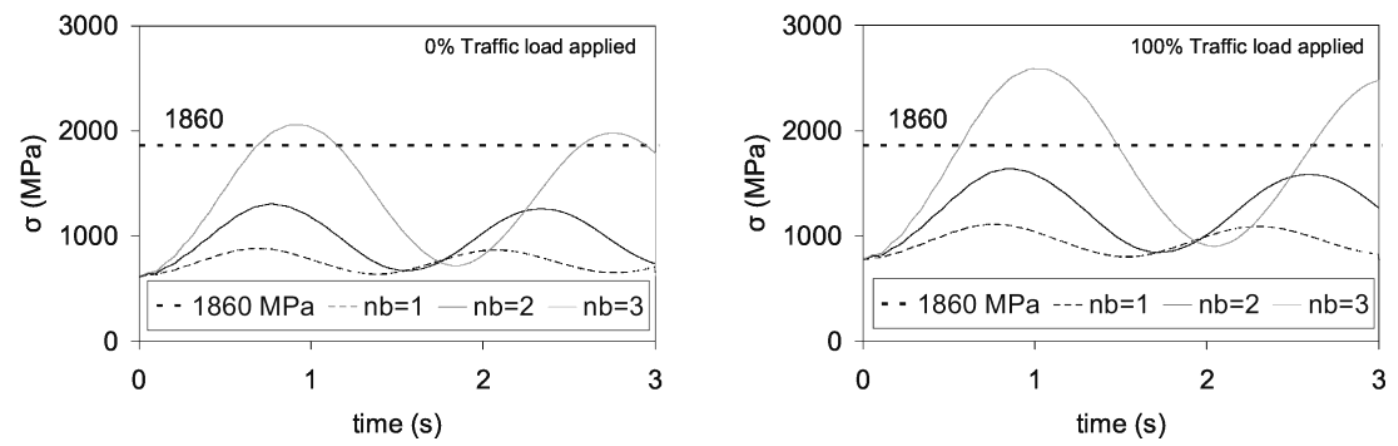

Fig. 13. Diagrams representing the design stresses in the stay cables $(\sigma)$ against time due to the breakage of a certain number of stay cables $(n b)$ in the multiple-strut bridge (deviators without clamps), when $0 \%$ and $100 \%$ of the traffic live load is applied, and the resistances of the stay cables. 
Cite this paper as: Ruiz-Teran AM, Aparicio AC, 2009, Response of under-deck cable-stayed bridges to the accidental breakage of stay cables, Engineering Structures, Vol:31, ISSN:0141-0296, Pages:1425-1434 [DOI: 10.1016/j.engstruct.2009.02.027]

a)

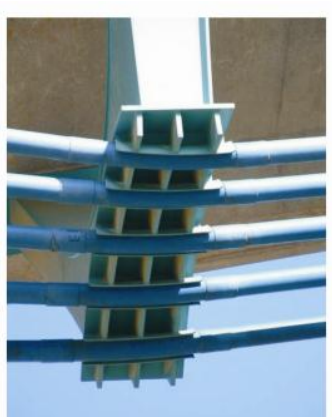

b)

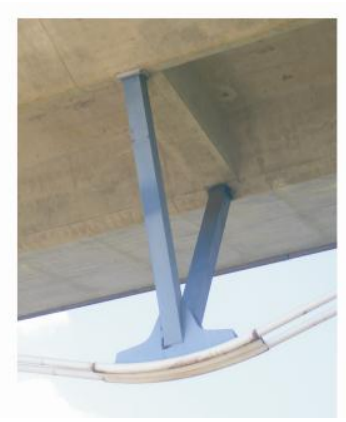

c)

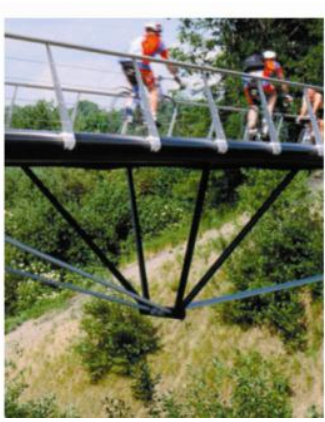

d)

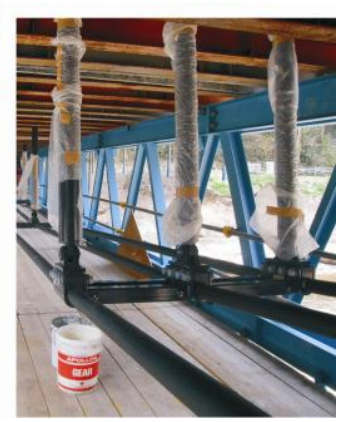

Fig. 14. Deviators a) with saddles, in Truc de la Fare overpass (courtesy of Nicolas Janberg,

www.structurae.de); b) with guide-tubes, in Osormort viaduct; c) with intermediate anchorages, in Jumet footbridge (courtesy of Jean Marie Cremer, Bureau Greisch); and d) with clamps, in Seiryuu footbridge (courtesy of Meguru Tsunomoto, Oriental Construction Co). 
Cite this paper as: Ruiz-Teran AM, Aparicio AC, 2009, Response of under-deck cable-stayed bridges to the accidental breakage of stay cables, Engineering Structures, Vol:31, ISSN:0141-0296,

Pages:1425-1434 [DOI: 10.1016/j.engstruct.2009.02.027]

\section{Table 1.}

Maximum and minimum dynamic and static values of the bending moments, shear and axial forces, and axial stresses and their corresponding $D A F \mathrm{~s}$, in certain sections of the two-strut bridge under the breakage of one central stay cable when deviators have clamps and no traffic load is applied.

\begin{tabular}{|c|c|c|c|c|c|}
\hline & $\begin{array}{l}\text { Maximum } \\
\text { dynamic } \\
\text { value }\end{array}$ & $\begin{array}{l}\text { Minimum } \\
\text { dynamic } \\
\text { value }\end{array}$ & Static value & $\mathrm{DAF}^{+}$ & DAF \\
\hline $\begin{array}{l}\text { Bending moment in S1 } \\
\text { (MN.m) }\end{array}$ & 1.965 & -0.521 & 0.768 & 2.53 & -0.678 \\
\hline $\begin{array}{l}\text { Bending moment in S2 and } \\
\text { S3 (MN.m) }\end{array}$ & 1.94 & 0 & 1.365 & 1.42 & 0 \\
\hline $\begin{array}{l}\text { Bending moment in S4 } \\
\text { (MN.m) }\end{array}$ & 3.811 & -1.14 & 1.365 & 2.79 & -0.84 \\
\hline Shear force in S1 (MN) & 0.063 & -0.162 & -0.051 & 3.18 & -1.24 \\
\hline Shear force in $\mathrm{S} 2(\mathrm{MN})$ & 0.187 & -0.433 & -0.051 & 8.49 & -3.67 \\
\hline Shear force in $\mathrm{S} 3(\mathrm{MN})$ & 0.453 & -0.311 & 0 & $\rightarrow+\infty$ & $\rightarrow-\infty$ \\
\hline Shear force in $\mathrm{S} 4(\mathrm{MN})$ & 0.052 & -0.041 & 0 & $\rightarrow+\infty$ & $\rightarrow-\infty$ \\
\hline Axial force in S1 (MN) & 3.884 & -2.366 & 0.163 & 23.83 & -14.52 \\
\hline Axial force in S2 (MN) & 5.087 & -2.228 & 0.163 & 31.21 & -13.67 \\
\hline Axial force in S3 (MN) & 5.237 & -2.263 & 0.171 & 30.62 & -13.23 \\
\hline Axial force in S4 (MN) & 4.845 & -2.048 & 0.171 & 28.33 & -11.98 \\
\hline Axial stress in S5 (MPa) & 37.594 & -97.903 & -4.734 & 20.68 & -7.94 \\
\hline Axial stress in S6 (MPa) & 163.220 & 0 & 120.515 & 1.35 & 0 \\
\hline
\end{tabular}

